\title{
Stroke in children
}

\author{
Eduardo Mekitarian Filho, ${ }^{1}$ Werther Brunow de Carvalho²
}

\begin{abstract}
Objectives: To summarize 1) the definitions and epidemiological features of stroke in children; 2) the main risk factors that can lead to stroke in pediatrics and neonatology; 3 ) the main pathophysiological features involved in the genesis of brain injury in stroke; 4) the clinical manifestations and imaging diagnosis; and 5) the latest recommendations concerning the support measures, treatment, and prophylaxis of stroke in children.

Sources: A review of the literature published in PubMed, EMBASE, and SciELO databases using the search terms stroke, pediatrics, and neonatology was performed, including relevant references from the chosen texts.

Summary of the findings: Stroke in children are rare conditions, with incidence rates among two and eight per 100,000 children up to 14 years, and most cases show an underlying disease such as heart diseases, prothrombotic conditions, sickle-cell disease, and vascular malformations. There are no specific guidelines currently in place for the treatment of stroke in children, although central elements include support treatment, monitoring, and anticoagulation as secondary prevention in certain cases. Prognosis depends on the extent of brain damage and the underlying disease but recurrence rates are high in most cases.
\end{abstract}

Conclusions: Early diagnosis of stroke in children is very important and pediatricians should be aware of the lack of specificity of the symptoms to avoid late sequelae and improve life quality.

J Pediatr (Rio J). 2009;85(6):469-479: Stroke, pediatrics, neonatology, intensive care, anticoagulants.

\section{Introduction}

Strokes in children are rare but increasingly important conditions due to the severity of their complications and diverse diagnostic differentials. Diagnosis requires a high level of clinical suspicion since the initial signs and symptoms manifested may lack specificity, with clinical presentations of other neurological diseases or non-central nervous system related conditions. Studies have shown a time lag between onset of clinical manifestations and diagnosis of between 35 and $72 \mathrm{~h} .{ }^{1}$ A retrospective analysis published by McGlennan et al. ${ }^{2}$ studied 50 children with acute stroke or transient ischemic attack. In $24 \mathrm{~h}$ after the onset of symptoms, $64 \%$ of the patients did not have a consult with a pediatric neurologist and $39 \%$ of them did not have an initial neuroimaging in the same time. The diagnosis was performed in more than $24 \mathrm{~h}$ in most children in this study. Adult stroke has different risk factors, clinical manifestations and outcomes comparing to pediatric stroke. ${ }^{3}$ The rationale behind this update is to assess the main pathophysiological mechanisms that lead to stroke in children and review the latest recommendations on management of stroke.

1. Mestrando, Pediatria e Ciências Aplicadas à Pediatria, Universidade Federal de São Paulo - Escola Paulista de Medicina (UNIFESP-EPM), São Paulo, SP, Brazil. Médico pediatra. Especialista, Pediatria e Terapia Intensiva Pediátrica, Sociedade Brasileira de Pediatria e Associação de Medicina Intensiva Brasileira. Médico intensivista, Unidade de Terapia Intensiva Pediátrica, Hospital Santa Catarina, São Paulo, SP, Brazil. Médico intensivista, Unidade de Terapia Intensiva Pediátrica, Hospital Pronto-Socorro Infantil Sabará, São Paulo, SP, Brazil.

2. Professor titular, área Neonatologia e Cuidados Intensivos, Departamento de Pediatria, Faculdade de Medicina, Universidade de São Paulo (USP), São Paulo, SP, Brazil. Professor livre-docente, Pediatria, UNIFESP-EPM, São Paulo, SP, Brazil. Chefe, Unidade de Terapia Intensiva Pediátrica, Hospital Santa Catarina, São Paulo, SP, Brazil. Chefe, Unidade de Terapia Intensiva Pediátrica, Hospital Pronto-Socorro Infantil Sabará, São Paulo, SP, Brazil.

This study was conducted at Universidade Federal de São Paulo - Escola Paulista de Medicina (UNIFESP-EPM), São Paulo, SP, Brazil. No conflicts of interest declared concerning the publication of this article.

Suggested citation: Mekitarian Filho E, de Carvalho WB. Stroke in children. J Pediatr (Rio J). 2009;85(6):469-479.

Manuscript submitted May 27 2009, accepted for publication Jun 222009.

doi:10.2223/JPED.1944 


\section{Definitions}

A stroke is characterized by clinical and neurological manifestations of stroke, together with radiological evidence of ischemia or infarct in a given arterial territory (acute ischemic stroke, AIS), or hemorrhage (hemorrhagic stroke, HS). ${ }^{4}$ Symptoms of stroke which last less than 24 $\mathrm{h}$ are called transient ischemic attacks. ${ }^{5}$ Strokes can be divided into neonatal strokes, which encompass pre-natal, perinatal (between 28 weeks' gestation and 7 days of life), and neonatal (first month of life) periods, and into nonneonatal or childhood strokes (beyond 1 month of age). Differentiating between pre-natal and perinatal conditions can be difficult, so some authors group these two periods into a single category.

\section{Epidemiological features}

The incidence of stroke in children ranges from two to eight per 100,000 up to 14 years per year, comprising similar proportions of AIS and HS. ${ }^{6}$ Excluding the first year, this rate falls by $50 \%$. American data show that 3,000 children are affected per year. Perinatal and neonatal strokes give an incidence of 10 to 18 in 100,000 live births, while studies have reported rates of up to $63 / 100,000 .{ }^{7}$ In view of its different clinical manifestations, its diverse causes and low suspicion for stroke in pediatrics, these data may underestimate the true incidence of stroke in this group. Stroke recurrence in children can reach $20 \%$, and in the presence of multiple risk factors recurrence can be as high as $42 \% .{ }^{8}$

A demographic survey conducted between 1979 and 1998 showed a significant decrease $(58 \%)$ in death from stroke in children. This survey revealed higher risk of mortality in black children (after exclusion of sickle-cell cases), with a relative risk of 1.75 , and in male children (relative risk of 1.21 excluding AIS). ${ }^{9}$

One of the first epidemiological findings from the International Pediatric Stroke Study found a male predominance in childhood AIS in all age groups studied. ${ }^{10}$ During the period of 4 years, 1,187 children with AIS or cerebral sinovenous thrombosis were studied in 30 centers located in 10 countries including all continents. In the neonatal period, $61 \%$ of the patients with AIS were boys ( $p=0.011)$; in childhood, $59 \%$ were boys ( $p=0.002)$; and in all ages, $60 \%$ were boys ( $p<0.0001)$, confirming a male predominance as described in former studies.

\section{Etiology and risk factors}

The risk factors for pediatric stroke are manifold and differ from those in adult stroke (including hypertension, atherosclerosis, smoking and obesity). The majority of AIS have underlying diseases such as sickle-cell and congenital or acquired cardiac diseases, whereas causes of HS include vascular malformations and trauma. Almost $30 \%$ of pediatric strokes and most newborn strokes have no evident risk factors. ${ }^{11}$ The major causes of stroke in children are as follows:

- Cardiac disease - congenital (aortic stenosis, defects in atrial or ventricular septum, aorta coarctation, patent ductus arteriosus) or acquired (arrhythmias, endocarditis, myocarditis, rheumatic disease, atrial myxoma);

- Hematologicaldisease-sickle-celldisease(SCD), leukemia or lymphomas, polycytemia, thrombocytosis;

- Coagulopathies - deficiencies in protein S or C, vitamin $\mathrm{K}$, antithrombin III, factors V Leiden, VII or XIII; lupic anticoagulant, oral birth control pills, pregnancy;

- Vasculitis - post-infectious (meningitis, varicella, HIV, mycoplasma), immunomediated (Henoch-Schönlein purpura, systemic lupus erythematosus), post-radiation or chemotherapy, adverse reactions to medications;

- Vascular anomalies - aneurysms, arteriovenous malformations, Moyamoya disease, arterial dissection;

- Venous infarcts - cerebral sinovenous thrombosis, shock;

- Metabolic disorders - mitochondrial encephalomyopathy, lactic acidosis and stroke-like episodes (MELAS syndrome), homocystinuria and mutation in the methyltetrahydrofolate reductase (MTHFR) gene, mitochondrial diseases, lipid anomalies;

- Vasospasm - migraine, drug use (cocaine, glue);

- Trauma and other causes - subdural and epidural hematomas, subarachnoid hemorrhage, spontaneous or traumatic dissection, dehydration, brain tumor.

Ganesan et al. ${ }^{12}$ published a study showing risk factors for recurrence of AIS in children. Their study found a recurrence rate of $37 \%$ within 1 to 11.5 years of the first stroke. Moyamoya disease and low birth weight were independent risk factors for recurrence in this group. Prothrombotic states were also risk factors. Other factors associated with radiological recurrence included previous transient ischemic attack, bilateral infarct, underlying diseases and leukocytosis.

\section{Perinatal ischemic stroke}

Defined as a group of heterogeneous conditions with focal disruption of cerebral blood flow secondary to arterial or cerebral venous thrombosis or embolization, between 20 weeks of pregnancy through the 28th postnatal day, and confirmed by neuroimaging or neuropathological studies. ${ }^{13}$ Clinical manifestations in this group are even less specific, ${ }^{14}$ the most common being seizures, apnea, and decreased level of consciousness. In the pediatric population, $25 \%$ of 
AIS and $43 \%$ of sinovenous thrombosis events occur during the perinatal age. ${ }^{15}$

The main risk factors for perinatal stroke include maternal, placental, hematologic, and cardiac. Primiparity, infertility, preeclampsia and prolonged rupture of membranes are included as risk factors. Early in the neonatal age, manifestations of prothrombotic conditions may appear in 20 to $68 \%$ of neonates with AIS. Embolisms can be found in neonates with heart diseases.

In preterm newborns, intracranial hemorrhage, mainly in very preterm infants (less than 28 weeks of pregnancy), is the most common event observed. As the brain blood flow in the newborn is directly correlated to systemic blood pressure, hypotension can cause a decrease in brain blood flow and consequently lesion of the germinal matrix. The latter can be related to other situations such as rapidly saline infusion, pneumothorax or interstitial emphysema. Intracranial hemorrhage may occur in about $25 \%$ of newborns with birth weight between 501 and $750 \mathrm{~g}$ and about $12 \%$ with birth weight between 751 and $1,000 \mathrm{~g}^{16}$

Pregnancy itself raises risk of thrombotic events, largely due to low levels of activated protein S and C. ${ }^{17}$ Intracranial hemorrhages in neonates may present no symptoms, even in moderate to severe hemorrhages because of the lack of specificity of the symptoms at this age. ${ }^{18}$

In spite of being a widely accepted measure for newborns, lack of administration of vitamin $\mathrm{K}$ may cause late hemorrhagic disease in infants aged between 2 and 12 weeks, with severe neurologic impairment. It is an alert and pediatricians should be aware of the recommended prophylaxis for the hemorrhagic disease of the newborn with $1 \mathrm{mg}$ of intramuscular vitamin K. ${ }^{19}$

Strokes account for approximately $10 \%$ of the seizures during the neonatal age, and most often manifest as focal motor crises involving one extremity. These events are strongly associated with cognitive and/or motor sequelae during childhood, with some degree of compromise found in 28 to $58 \%$ of stroke cases. A retrospective analysis conducted by Golomb et al. which assessed follow-up in children diagnosed with perinatal stroke revealed that approximately $60 \%$ of these cases had developed epilepsy at 6 months of age. One third of these children resolved without the need for anticonvulsant therapy. ${ }^{20}$ Ohlweiler et al. found significant impairment in neurological development in neonates with HS analyzing muscle tone, reflexes, strength, and head control at 6 months of corrected age. ${ }^{21}$

In newborn infants with HS, care should be taken to maintain platelets at normal levels while replacing coagulation factors and vitamin $\mathrm{K}$ in specific cases when necessary. Hydrocephalus is common after hemorrhagic events and must be managed using ventricular drainage if persistent or high volume. In this age group, there are no recommendations for use of anticoagulants or thrombolysis in ischemic events due to lack of controlled studies.

\section{Stroke and cardiac diseases}

Studies have shown a two- to three-fold higher prevalence of anatomic cardiac anomalies in stroke cases compared to the general population. ${ }^{22}$ Overall, heart disease may account for up to $1 / 3$ of all AIS in children. Among congenital diseases, the cyanogenic ones with right-toleft shunts have the highest complication rates, including hypoxemia, polycytemia or cyanosis, and may evolve with cerebral ischemia in up to $4 \%$ of cases.

During the preoperative period, children with acute congenital diseases, hemodynamically stable or otherwise, are at high risk of compromised blood pressure and brain hypoperfusion ${ }^{23}$ due to reduced cerebral perfusion resulting from low cardiac index, arrhythmias or patent ductus arteriosus.

However, the highest risk occurs during the perioperative period, especially with extracorporeal membrane oxygenation (ECMO). Some degree of neurological dysfunction is observed in 25 to $45 \%$ of children undergoing ECMO, ${ }^{24}$ stemming from three main factors: systemic inflammatory response syndrome, micro and macroemboli, and insufficient cerebral blood flow to supply the metabolic needs, such as during episodes of hypertension or cardiorespiratory arrest. ${ }^{25}$ The incidence of confirmed AIS in this situation ranges from 1 to $15 \%$. The main conditions that cause brain injury are the systemic inflammation, microvasculopathy causing decreased cerebral blood flow, platelet aggregation through neutrophil activation and direct injury by oxygen free radicals through endothelial activation.

Chow et al. ${ }^{26}$ assessed risk factors associated with AIS occurrence post-ECMO, and found statistically significant correlations between patient age at time of surgery, total time on ECMO, and shorter preoperative activated partial thromboplastin time.

Other risk factors include marked hypothermia during ECMO which, despite its neuroprotective effect and reduced brain metabolic rate, has a series of deleterious effects; limited capacity to autoregulate cerebral blood flow during the surgical procedure due to fixed cardiac index, and finally constant shifts in blood $\mathrm{pH}$ during hypothermia which lead to alkalemia, with lower oxygen availability for tissues.

According to Miller et al., ${ }^{27}$ mild neuropsychomotor developmental delays to severe brain injury are observed in 23 to $60 \%$ of children.

Another factor for AIS in cardiac disease is bacterial endocarditis with septic embolisms. The incidence is not known in children but reports in adults have shown a $40 \%$ incidence of associated neurologic events. Studies have 
described good prognosis in this high-risk group, with a lower probability of motor sequelae following treatment for endocarditis. ${ }^{28}$

\section{Stroke and sickle-cell disease}

SCD is one of the leading risk factors for AIS, with incidence ranging according to age. The incidence is $0.13 \%$ in infants younger than 2 years, rising to $1 \%$ of cases into 2-5 years and is $0.79 \%$ within $6-9$ years. AIS incidence in children with SCD may be up to 280 times higher than in the pediatric population. ${ }^{29}$ Considering findings of cerebral ischemia on magnetic nuclear resonance studies (MR), lesions are found in up to $22 \%$ of infant patients. 30,31

Risk factors include previous transient ischemic events, high blood flow speed on transcranial Doppler, arterial hypertension, history of acute thoracic syndrome, low levels of hemoglobin, and high leukocyte count, with the latter being relevant in cases of HS in children with SCD.

Although vaso-occlusion of the microcirculation represents an important cause of morbidity in SCD, cerebrovascular disease manifests as vasculopathy of great vessels distal to the internal carotid artery, and in proximal sections of middle and anterior cerebral arteries. In the early 1980 s, Gerald et al. ${ }^{32}$ demonstrated that the lesions outlined above affected up to $80 \%$ of patients to some extent. These findings are corroborated by MR imaging that shows high percentages of distal occlusions of great vessels. The combination of arterial dilation and weak elastic support raises chances for HS. 33,34

Major infarcts in the territory of the middle cerebral artery secondary to carotid lesions are also a common finding. Smaller lesions are also found involving the basal ganglia and white matter.

Over a 4-year period, two studies 35,36 found high rates of stroke recurrence in children with SCD of nearly $30 \%$.

Initial therapeutic measures for pediatric stroke are similar to those adopted in children with SCD, with special attention to correction of dehydration, hypoxemia and hypotension. Blood transfusions are indicated in acute cases of stroke to reduce levels of hemoglobin $\mathrm{S}$ to less than $30 \%$ while maintaining hemoglobin between 10 and $12.5 \mathrm{~g} / \mathrm{dL} .{ }^{37}$ In addition, the child must follow a regular transfusion program to reduce AIS secondary to SCD, with care concerning potential iron poisoning. Annual transcranial Doppler has also been recommended in children aged between 2 and 16 years (in cases of normal exams), with more frequent exams in the event of altered findings of arterial blood flow greater than $200 \mathrm{~cm} / \mathrm{s}$. A prevention rate of $90 \%$ in the occurrence of stroke has been described in asymptomatic children with high blood flows on Doppler exams and undergoing regular blood transfusion programs. ${ }^{38}$ Management without significant supporting evidence may be employed in refractory and/or recurrent cases including use of hydroxyurea (particularly in children not eligible for multiple transfusions), bone marrow transplant and revascularization surgery, mainly in patients with multiple lesions.

\section{Stroke and Moyamoya disease}

Moyamoya (a Japanese word for "puff of smoke" referring to the appearance of arterial collateral branches on angiography) disease is characterized by chronic, progressive stenosis of the intracranial distal portion of the internal carotid artery and less commonly by stenosis of the proximal portions of anterior, middle, basilar or posterior cerebral arteries. The disease is responsible for up to $6 \%$ of strokes in Western countries, but has greater incidence in oriental children affecting three in every 100,000 children per year, with a female-male ratio about $1: 8$. Two peaks of age at the onset of the symptoms are suggested - the first at 5 years of age and a lower peak at about 40 years old. ${ }^{39}$

Diagnosis requires stenosis involving the distal part of the bifurcation of the internal carotid artery and proximal portions of the middle and anterior cerebral arteries, the finding of arterial collateral branches and the characteristic of bilateral alterations. This definition remains controversial and in 2002 Sebire et al. ${ }^{40}$ proposed that a finding of unilateral stenosis associated with typical collateral branches should also define the disease. The name Moyamoya disease is also given to the finding of these radiological features without presence of risk factors, while Moyamoya syndrome denotes the association of the features described in conjunction with factors such as SCD, neurofibromatosis or infections. Concerning Moyamoya syndrome, Dobson et al. ${ }^{41}$ carried out a retrospective analysis of 44 children with SCD, and the chances of recurrent AIS in those with Moyamoya syndrome over the long term was almost twice as high as in the group without these radiological features. From a histological standpoint, proliferation of the intima layer of arteries, fibrosis, and loss of elasticity lead to progressive arterial luminal obstruction. 42

Junqueira et al. ${ }^{43}$ carried out a meta-analysis of patients with Down syndrome and Moyamoya disease. It was possible to conclude that mean age of onset of the symptoms was 2 to 7 years old, hemiparesis was the most frequent symptom in almost $78 \%$ of the patients and most of them presented with AIS (about 76\%).

Little is known about the pathogenesis of the disease but there is evidence, from the fact that 7 to $12 \%$ of firstdegree oriental relatives harbor the disease, that genetic factors play an important role.

Children with Moyamoya disease can benefit from surgical revascularization, particularly those with progressive neurological symptoms or evidence of inadequate blood 
flow and/or collateral circulation and in whom surgery is not contraindicated. Use of anticoagulants is not routinely recommended due to risk of hemorrhagic events.

Approximately $2 / 3$ of the patients with the disease, when untreated, present recurrent AIS. Children can show some atypical symptoms such as syncope, paraparesis or involuntary movements, characteristically induced by hyperventilation. About $25 \%$ of the children with the disease have complaints of headache, even 1 year after revascularization surgery. Bleeding is a symptom more common in adults due to the rupture of dilated vessels or aneurysms, and may be present in about half of adult patients. Prognosis in this disease is related to the speed and extent of vascular occlusion, patterns of collateral circulation, age at onset of symptoms, degree of neurological deficit and size of ischemic brain area on imaging studies. Pediatric patients rarely develop AIS after surgery.

\section{Arteriopathy}

It is estimated that about $60 \%$ of previous healthy children have degrees of stenosis of some cerebral arteries when diagnosed with AIS. Excluding some known causes of arteriopathy such as arterial dissection or Moyamoya disease, many have a focal stenosis without known causes. These children are now diagnosed with focal cerebral arteriopathy of childhood (FCA), as defined by the International Pediatric Stroke Study. Amlie-Lefond et al. ${ }^{44}$ found that $25 \%$ of children with AIS had FCA with predictors for this disease, such as age between 5 to 9 years, recent respiratory infections or SCD.

\section{Stroke and prothrombotic conditions}

Prothrombotic disease may be present in up to $50 \%$ of AIS. The main associated conditions are protein $\mathrm{C}$ or S, antithrombin III and plasminogen deficiencies, as well as factor $\mathrm{V}$ Leiden mutations, polymorphisms of methylenetetrahydrofolate dehydrogenase enzyme (major cause of homocystinuria), homocysteinemia and high levels of lipoprotein A. Children who are heterozygote for factor $\mathrm{V}$ Leiden mutation have a seven-fold higher risk of developing ischemic events. ${ }^{45,46}$

A systematic review ${ }^{47}$ published in 2002 shows that these laboratorial changes are present in a greater number of children with stroke than those without the disease, thereby justifying screening for thrombophilia in all children with first AIS.

\section{Hemorrhagic stroke}

It encompasses both spontaneous intraparenchymatous hemorrhage and non-traumatic subarachnoid hemorrhage. ${ }^{48}$
Retrospective analyses have identified the leading causes as presence of arteriovenous malformations, hematologic diseases (evolving with thrombocytopenia; hemophilia and other coagulopathies), brain tumors, cavernous hemangiomas, vasculopathy, and cerebral and systemic infections. With regard to intraparenchymatous hemorrhage, arteriovenous malformations can account for up to half of the cases observed. The incidence of HS in children is about 1.1 per 100,000 children, being almost $80 \%$ of cerebral hemorrhage and $20 \%$ of subarachnoid hemorrhage. Jordan et al. ${ }^{49}$ verified a cohort of 2.3 million children in a mean time of 3.5 years and found 116 cases of spontaneous HS. Thirteen per cent of these children had cerebral aneurysms and considering only subarachnoid hemorrhage almost $57 \%$ of the children affected had cerebral aneurysms, concluding that these malformations may account in large number in pediatric acute HS patients. In hematologic disorders, patients with immune thrombocytopenic purpura carry a 0.1 to $1 \%$ risk of developing a hemorrhagic event, this risk being directly proportionate to platelet count, as demonstrated by Butros et al. 50 in 2003 . Approximately $71 \%$ of children described in this retrospective analysis had platelet counts less than $10,000 / \mathrm{mm}$.

In 2003, Meyer-Heim et al. 51 reported the risk factors for HS including age (less than 3 years), score less than seven on the Glasgow coma scale, hemorrhage in the infratentorial region and underlying hemorrhagic disease.

In cases of HS, consultation with a neurosurgeon allied with imaging investigations using magnetic resonance angiography or conventional angiography are indispensible in achieving surgical management. Disturbances in coagulation and platelets should be readily treated. No sole therapeutic action used in isolation is efficacious in treating this patient group. Use of corticosteroids is not recommended based on clinical trials with adult patients with intraparenchymal hemorrhage; in addition, hyperglycemia may occur as a common side effect and is a marker of bad prognosis in patient outcome.

Advances in neurosurgical techniques and early diagnosis using imaging have substantially reduced the morbidity and mortality associated with pediatric HS. Studies have shown mortality to be high and variable, reaching rates of up to $54 \%$, while significant neurological sequelae are seen in approximately $42 \%$ of child survivors.

\section{Other causes of stroke in children}

Vasculitis in children mostly arises from infectious events and is hard to diagnose due to the low specificity of the diagnostic methods available. This diagnosis should be suspected in recurrent events or in those associated with fever, multifocal events, associated skins lesions, glomerulopathies or high values in inflammatory tests. Infections such as tuberculous meningitis, post-varicella 
encephalopathy, aspergillosis, fungal infections or by other virus such as HIV and Coxsackie may also be involved. Autoimmune vasculitis, as seen in children with systemic lupus erythematosus, may cause ischemic lesions through several mechanisms such as release of emboli due to endocarditis, presence of anti-phospholipid antibodies, and vasculopathy which is commonly associated with these pictures.

In children with varicella, the first year post-infection represents the high risk window for stroke occurrence. Inflammatory vasculopathy, probably following migration of the virus through the trigeminal nerve and cervical vasculature, is the mechanism associated with varicella. ${ }^{52}$ A large retrospective cohort study published by Donahue et al. ${ }^{53}$ was performed to identify the magnitude of new stroke cases after varicella vaccination. Almost 1,250,000 children were vaccinated and 203 new AIS diagnosis were made in the first year after vaccination. None of these cases occurred in the first 30 days after vaccination and multivariate analysis showed no association between encephalitis and varicella vaccination. Most of the cases had well known risk factors, such as cardiac diseases, vascular conditions and SCD.

Critically ill children were studied by Jordan et al. ${ }^{54}$ In this retrospective analysis, $93 \%$ of the patients admitted in the pediatric intensive care unit had at least one risk factor for AIS. In addition, critically ill children with stroke had 60 times more chances to die than non-critically ill children.

Sinovenous thrombosis of dura mater presents as a frequent manifestation of stroke during the neonatal age, usually with seizures and lethargy. Disjunctions and overlapping of cranial sutures during birth may affect cerebral sinus structures, thereby raising the risk of stroke. The majority of thromboses occur in the superior sagittal sinus with or without associated bilateral sinus thrombosis. 55 The finding of perinatal asphyxia is also commonly concomitant with sinovenous thrombosis, and can represent a risk factor for this thrombosis. Coagulation disorders are found in up to $20 \%$ of newborn infants with sinovenous thrombosis. 56,57

Patients diagnosed with migraine with aura may be at higher risk of AIS, particularly in early adolescence and in females using birth control pills. Other situations, such as hypertension, dyslipidemia, and diabetes mellitus in children, do not carry proven higher risk for stroke. ${ }^{58}$

\section{Pathophysiological aspects}

Cerebral lesions stemming from ischemic or hemorrhagic injury are the product of highly complex mechanisms. Since brain tissue has a high metabolic requirement for oxygen and glucose, any interruption in circulation in the areas affected by vascular occlusion leads to depletion of metabolic substrates in a matter of minutes, a situation exacerbated by subsequent build up of toxic metabolites, energy deficits, and damage to affected cells.

Based on a review conducted in 2004, Mergenthaler et al. ${ }^{59}$ compiled a list of the main features involved in the genesis of brain injury. The most important is the penumbra zone, the area that surrounds the infarcted area and is affected by cell apoptosis and proinflammatory cytokines representing $50 \%$ of brain volume that goes on to infarct. Other aspects include cellular toxicity due to excitotoxic amino acids and oxygen free radicals leading to osmotic lysis of the neurons, tissue acidosis secondary to anaerobic metabolism causing neuronal malfunctioning, breakdown of blood-brain barrier induced by metalloproteinases and finally immunosuppression causing reduced lymphocytes and synthesis of interferon-gamma due to activation of the sympathetic autonomous nervous system.

\section{Clinical findings}

The clinical manifestations of pediatric stroke are diverse and often non-specific. Children who present at least one of the following clinical characteristics should undergo compulsory screening for stroke: acute onset of focal neurological deficit of any duration; unexplained change in level of consciousness, particularly when associated with headache; seizures during the neonatal period, and in the post-operative period in children undergoing cardiac surgery. 60

Seizures are the most common finding during the neonatal age and their presence early in diagnosis appears to predispose the child to later epilepsy in 8 to $12 \%$ of such cases. ${ }^{61}$ In fact, clinical changes, such as hemiparesis, are present in less than $25 \%$ of neonates with stroke. ${ }^{62}$

The finding of fontanel depression associated or otherwise with pulsatility along with head or cervical venous dilation should alert to the possibility of sinovenous thrombosis. Late appearance of hemiparesis is a common indicator of stroke occurrence in the neonatal period, generally occurring between 4 and 8 months of life. 63

As age increases, symptomatology tends to more closely resemble that of adults. The most commonly described symptoms include hemiparesis, decreased level of consciousness and cranial nerve lesions. Case series involving children older than 1 month show a rate of hemiparesis ranging from 85 to $100 \% .64,65$ Other symptoms include hemiplegia, monoparesis, dysphasia, headache, dizziness, and visual disturbances.

A review conducted in 2007 by Zimmer et al. ${ }^{66}$ found similar proportions of children with seizures or focal deficits ( $45 \%$ per group) in infants younger than 1 year of age. In older children, however, focal deficits were seven times more frequent than seizures. A recent review performed by 
Chadehumbe et al. ${ }^{67}$ showed that $58 \%$ of children with stroke presented seizures within $24 \mathrm{~h}$ of the onset of symptoms, with no differences found in the rate of seizures according to the subtype of the stroke.

Metabolic diseases such as MELAS syndrome are characterized by strokes with complete resolution of the neurologic symptoms, and events persisting after some years include sequelae, mainly visual. 68

\section{Diagnostic imaging methods}

Diagnosing stroke in children can present technical challenges in ascertaining the degree and site of brain damage. Computed tomography (CT) of the brain is deemed by most authors the most suitable imaging method by virtue of its swiftness, practicality and availability, being able to clearly reveal hemorrhagic events and differentiate them from ischemic events. In addition, $\mathrm{CT}$ is less dependent on the patient's clinical stability, a factor which often contraindicates use of MR in initial stages of the disease.

Cranial ultrasound is useful in the neonatal period for assessing intraventricular and germinal matrix hemorrhage. This exam can also detect abnormalities in cerebral blood flow in children suspected of presenting extracranial arterial dissection. Gauzzi et al. ${ }^{69}$ studied the use of the posterior fontanel in cranial ultrasound in intracranial hemorrhage in newborns. Usually, the anterior fontanel is most used but can miss occipital strokes and lesions in the occipital zone of the lateral ventricles. In this study almost $30 \%$ of mild hemorrhages were only diagnosed with the posterior fontanel ultrasound and other $30 \%$ of hemorrhages suspected by the anterior fontanel ultrasound were later confirmed with the posterior fontanel.

In children with $S C D$, use of transcranial Doppler provides valuable information on blood flow peak speed in terminal portions of the internal carotid artery or proximal portions of the middle cerebral artery, revealing higher risk of stroke at velocities exceeding $200 \mathrm{~cm} / \mathrm{s} .{ }^{70}$ However, studies have shown that lower speeds of around $128 \mathrm{~cm} / \mathrm{s}$ also point to higher risk and the need to perform more in-depth imaging exams in such patients. ${ }^{71}$

A retrospective study by Steen et al. ${ }^{72}$ found high rates of radiological changes in children with SCD. Radiological evidence of cerebral infarct was found in 35\% of children studied, none of whom had previously been diagnosed with stroke. Moreover, occurrence of vascular lesions in children with hemoglobin SC patterns is 35\% lower than in those with hemoglobin SS.

Magnetic resonance angiography is considered the gold standard for diagnosing not only brain lesions but also possible vascular obstruction and/or lesions which triggered the ischemic event. When performed early, this exam can detect the beginnings of cerebral infarcts before tomographic studies ${ }^{73}$ and should always be indicated if confirmation of AIS has previously been made by any other imaging method. Cerebral digital angiography should always be considered when negative or conflicting findings are found on MR or when no radiological or laboratorial evidence is found for the cause of the stroke. The exam is also indicated in children with Moyamoya disease who are scheduled for revascularization surgery. ${ }^{74}$ As described by Matta et al. ${ }^{75}$ in retrospective case series, almost $83 \%$ of children with AIS had obstruction of the middle cerebral artery, confirmed by other studies as the most commonly involved artery in childhood stroke.

Imaging exams can help reveal the etiology of the stroke based on the brain infarct pattern. Findings of multiple infarcts in different areas of arterial distribution are suggestive of thromboembolytic events, while occipital and parietal infarcts with areas of intersection between venous territories are common in MELAS syndrome. Finally, ischemic distribution between the irrigation territories of different cerebral arteries (frontier zones) is common in hypotensive events, whereas a pattern of small multifocal lesions, mainly in the transition between white and gray matter, suggests vasculitis. ${ }^{76}$

Conventional angiography is superior to other vascular imaging approaches such as tomographic angiography or resonance angiography for diseases such as vasculitis, intracerebral arterial dissections and aneurysms. It is important to be aware of the main risks inherent to angiography, which include use of iodine contrast with its nephrotoxicity and hypersensitivity risks, besides the need for arterial puncture with risks of vascular lesion, bleeding, and thromboembolism.

\section{Other supplementary exams}

An echocardiogram may be helpful to diagnose patent foramen ovale; this abnormality can be up to four times greater in children with stroke with undetermined etiology than in the general population. ${ }^{77}$

Other causes of acute neurological deficit are included in the differential diagnosis of stroke such as seizures, trauma, migraine, ventricular obstruction in cases of hydrocephalus, brain abscess, metabolic diseases, reaction to drugs, meningitis, syncope and drug poisoning.

\section{Treatment}

No standard approach currently exists that pools evidence based on double-blind or randomized studies, or indicates specific recommendations for treating stroke cases in the pediatric population. ${ }^{78}$

The main initial approach is aimed at stabilizing the child from the time of admission to the emergency room up to 
treatment in intensive care. In contrast to adults, stroke in children seldom manifests as severe and acute systemic pictures requiring immediate resuscitation measures. However, ensuring permeability of the airways, supplying oxygenation with sufficient ventilation for hypoxemic children and providing adequate circulation are fundamental initial steps.

Metabolic, hydric and body temperature controls are of paramount importance. As described in Table 1, it is important to readily obtain blood samples in the emergency room for blood count, prothrombin and thrombin times and electrolytes - these disturbances may be early corrected. Since no pediatric studies attest the safety and efficacy of hypothermia as a clinical measure for reducing cerebral metabolic rate, its routine use cannot currently be indicated. Glycemic control in critically ill children also lacks specific protocols or controlled studies. Nonetheless, a large body of recent evidence points to the fact that hyperglycemia in critical children significantly raises morbidity and mortality in such patients. ${ }^{79}$ Dehydration and anemia are independent risk factors for occurrence of ischemic events, particularly thrombotic events during the neonatal period, and should thus be managed separately in all cases.

Body temperature control has a huge importance in patients with stroke. There are some explanations for the impact of fever in worsening brain injury after AIS: 1) increased levels of excitatory amino acids, free radicals and lactate; 2) breakdown of the blood-brain barrier; and 3) impairment in enzymatic functioning and reduced cytoskeletal stability. Greer et al. ${ }^{80}$ carried out a metaanalysis to find the effects of fever in acute stroke. Fever contributed with poor prognosis in stroke in almost all 39 studies, with an odds ratio of 1.5 for mortality, 1.3 for severe neurological deficit, 2.8 for higher intensive care unit length-of-stay and 3.2 for longer hospital stay.

\section{Anticoagulant and antiplatelet therapy}

The efficacy and safety of low-molecular weight heparin (LMWH) or unfractionated heparin (UFH) use has not yet been proven in pediatric patients, except for some case reports demonstrating safety in preventing thrombotic events after ischemic stroke. ${ }^{81}$

The anticoagulant therapy, either in the acute phase of stroke or for the chronic management, is one of the major issues described in the 2008 guidelines in Chest $^{82}$ and the American Heart Association (AHA). ${ }^{7}$ In AIS, the Chest guidelines recommend use of UFH or LMWH or aspirin (1 $\mathrm{mg} / \mathrm{kg} /$ day) until cardioembolic and dissection subtypes of stroke are excluded. The AHA recommendation addresses use of UFH or LMWH up to 1 week until the cause is determinate. 83

When it comes to cardiac diseases as causes of stroke, the Chest guidelines recommend use of LMWH for over 6 weeks. Surgical repair of the cardiac disease is the main step according to the AHA.

Table 1 - Supplementary exams for diagnosing stroke in children

\begin{tabular}{|c|c|}
\hline Exam & Comments \\
\hline $\begin{array}{l}\text { Cardiac disease assessment: ECG, echocardiogram, } \\
\text { and thoracic radiography }\end{array}$ & $\begin{array}{l}\text { Assessing source of embolisms, arrhythmias, and structural } \\
\text { abnormalities; lack specificity in the absence of clinical findings } \\
\text { of cardiac disease }\end{array}$ \\
\hline Cell blood count & $\begin{array}{l}\text { Non-specific findings for SCD, anemia, thrombocytopenia and } \\
\text { infectious diseases }\end{array}$ \\
\hline Coagulation tests & $\begin{array}{l}\text { Assessment of congenital or acquired coagulation } \\
\text { (hepatic disease, anticoagulation monitoring) }\end{array}$ \\
\hline Antinuclear factor & Initial triage to screen for systemic lupus erythematosus \\
\hline Hemoglobin electrophoresis & SCD diagnosis \\
\hline Lumbar puncture & $\begin{array}{l}\text { Detection of meningitis and/or encephalitis in children with } \\
\text { no clinical or radiologic signs of intracranial hypertension }\end{array}$ \\
\hline Lipid profile & Assessment of additional risk factors \\
\hline Hypercoagulability screening & $\begin{array}{l}\text { Determines levels of Protein C and S, antithrombin III, lupic anticoagulant, } \\
\text { anticardiolipin, urinary homocysteine }\end{array}$ \\
\hline Arterial lactate and pyruvate & Commonly high in MELAS disease \\
\hline HIV test & Known cause of stroke \\
\hline Toxicologic screening & In high-risk children \\
\hline $\begin{array}{l}\text { Electrolytes, renal function, arterial blood gases } \\
\text { and other tests }\end{array}$ & Clinical monitoring \\
\hline
\end{tabular}

ECG = electrocardiogram; HIV = human immunodeficiency virus; MELAS = mithochondrial encephalomyopathy, lactic acidosis and stroke-like episodes; SCD = sicklecell disease. 
As a secondary prevention, use of aspirin (1-5 mg/ $\mathrm{kg} /$ day) for over 2 years, once excluded dissection and cardioembolism, is recommend by the Chest guidelines; the same recommendation is given by the AHA statements.

A prospective cohort study published in 2001 by Sträater et al. ${ }^{84}$ found no difference in recurrence of ischemic events over the long term between children who used LMWH and those on acetylsalicylic acid as secondary prophylaxis.

\section{Thrombolysis in acute ischemic stroke}

Existing guidelines regarding management of stroke in adults cannot be applied to children since there are many age-related differences in the coagulation pathways, pathophysiology, and drug metabolism. Ganesan 85 identified three main factors that prevent extrapolating data from adult thrombolysis to children: 1 ) the diagnosis of ischemic stroke in children is usually delayed, as mentioned above; 2 ) the pathophysiology of pediatric stroke is not dominated by consequences of atheromatous diseases as in adults; and 3 ) the complete arterial occlusion in pediatric stroke is relatively rare, opposing the main indications of thrombolysis. The first pediatric trial had its guidelines recently published 86 (Thrombolysis in Pediatric Stroke, TIPS) and will comprise 30 international pediatric tertiary care institutions. The TIPS is a 5-year, prospective cohort study and will test the hypothesis that tissue plasminogen activator (tPA) can be given with safety in acute childhood stroke. This study is scheduled to begin this year.

Isolated case reports assessing safety and efficacy using thrombolysis in ischemic stroke in children are available in the literature. Arnold et al. ${ }^{87}$ described two cases of ischemic stroke treated with urokinase, both of them with no etiological diagnosis and with poor neurologic outcome. There are also reports of diffuse hemorrhage in children due to alteplase use for extracerebral thrombolysis in up to $11 \%$ of cases. 88,89

\section{Conclusions}

It is clear that the occurrence of pediatric stroke hinges on multifactorial etiology and is associated with the underlying disease in most cases. Diagnosis of stroke proves challenging, particularly in younger pediatric age groups, because symptoms are often unspecific in nature. Long-term neurologic sequelae and neuropsychomotor impairments are common, these being closely linked to the underlying disease and extent of cerebral lesions. ${ }^{90,91}$ Recurrence rates are high, justifying early diagnosis and primary or secondary preventative measures to reduce these complications. No standard treatment schemes have yet been proposed for managing stroke in children, with the majority of data having been drawn from consensus by specialists or extrapolated from reports in the literature on adult patients. Increased training of pediatricians in early recognition of signs and symptoms can contribute to more timely diagnosis and reduced sequelae.

\section{References}

1. Gabis LV, Yangala R, Lenn NJ. Time lag to diagnosis of stroke in children. Pediatrics. 2002;110:924-8.

2. McGlennan C, Ganesan V. Delays in investigation and management of acute arterial ischaemic stroke in children. Dev Med Child Neurol. 2008;50:537-40.

3. Goodman S, Pavlakis S. Pediatric and newborn stroke. Curr Treat Options Neurol. 2008;10:431-9.

4. Bernard TJ, Goldenberg NA. Pediatric arterial ischemic stroke. Pediatr Clin North Am. 2008;55:323-38.

5. Molofsky WJ. Managing stroke in children. Pediatr Ann. 2006;35:379-84

6. Jordan LC. Assessment and treatment of stroke in children. Curr Treat Options Neurol. 2008;10:399-409.

7. Roach ES, Golomb MR, Adams R, Biller J, Daniels S, Deveber G, et al. Management of stroke in infants and children: a scientific statement from a Special Writing Group of the American Heart Association Stroke Council and the Council on Cardiovascular Disease in the Young. Stroke. 2008;39:2644-91.

8. Lanthier S, Carmant L, David M, Larbrisseau A, de Veber G. Stroke in children: the coexistence of multiple risk factors predicts poor outcome. Neurology. 2000;54:371-8.

9. Fullerton $\mathrm{HJ}$, Chetkovich MD, Wu YW, Smith WS, Johnston SC. Deaths from stroke in US children, 1979 to 1998. Neurology. 2002;59:34-9.

10. Golomb MR, Fullerton HJ, Nowak-Gottl U, deVeber G. Male predominance in childhood ischemic stroke: findings from the International Pediatric Stroke Study. Stroke. 2009;40:52-7.

11. Pavlakis SG, Levinson K. Arterial ischemic stroke: common risk factors in newborns and children. Stroke. 2009;40:S79-81.

12. Ganesan V, Prengler M, Wade A, Kirkham FJ. Clinical and radiological recurrence after childhood arterial ischemic stroke. Circulation. 2006;114:2170-7.

13. Kirton A, deVeber G. Advances in perinatal ischemic stroke. Pediatr Neurol. 2009;40:205-14.

14. Laugesaar R, Kolk A, Tomberg T, Metsvaht T, Lintrop M, Varendi $\mathrm{H}$, et al. Acutely and retrospectively diagnosed perinatal stroke: a population-based study. Stroke. 2007;38:2234-40.

15. deVeber G. Stroke and the child's brain: an overview of epidemiology, syndromes and risk factors. Curr Opin Neurol. 2002;15:133-8

16. Silveira RC, Procianoy RS. Lesões isquêmicas cerebrais no recémnascido pré-termo de muito baixo peso. J Pediatr (Rio J). 2005;81: S23-32.

17. Nelson KB, Lynch JK. Stroke in newborn infants. Lancet Neurol. 2004;3:150-8.

18. Gupta SN, Kechli AM, Kanamalla US. Intracranial hemorrhage in term newborns: management and outcomes. Pediatr Neurol. 2009;40:1-12.

19. Grillo E, Silva RJ, Filho JH. Hemorragia intracraniana por deficiência de vitamina $\mathrm{K}$ em lactentes: relato de 2 casos. J Pediatr (Rio J). $2000 ; 76: 233-6$

20. Golomb MR, Garg BP, Carvalho KS, Johnson CS, Williams LS. Perinatal stroke and the risk of developing childhood epilepsy. J Pediatr. 2007;151:409-13 
21. Ohlweiller L, da Silva AR, Barros SV, Riesgo R, Rotta NT. Influence of intracranial hemorrhage and neonatal seizures on the neurological and psychomotor development of premature infants at Hospital de Clínicas de Porto Alegre, Brazil. Arq Neuropsiquiatr. 2003;61:902-5.

22. Wu LA, Malouf JF, Dearani JA, Hagler DJ, Reeder GS, Petty G et al. Patent foramen ovale in cryptogenic stroke: current understanding and management options. Arch Intern Med. 2004;164:2502.

23. du Plessis AJ. Mechanisms of brain injury during cardiac infant surgery. Semin Pediatr Neurol. 1999;6:32-47.

24. Chan AK, deVeber G, Gruenwald C, Yager J, Massicotte MP. Cardiopulmonary bypass and arterial ischemic stroke in infants and children. Prog Pediatr Cardiol. 2005;21:117-21.

25. Hayashida M, Kin T, Tomioka R, Orii H, Sekiyama H, Usui H et al. Cerebral ischaemia during cardiac surgery in children detected by combined monitoring of BIS and near-infrared spectroscopy. $\mathrm{Br}$ J Anaesth. 2004;92:662-9.

26. Chow G, Koirala B, Armstrong D, McCrindle B, Bohn D, Edgell D et al. Predictors of mortality and neurological morbidity in children undergoing extracorporeal life support for cardiac disease. Eur J Cardiothorac Surg. 2004;26:38-43.

27. Miller SP, McQuillen PS, Vigneron D, Glidden DV, Barkovich J, Ferriero DM et al. Preoperative brain injury in newborns with transposition of the great arteries. Ann Thorac Surg. 2004;77:1698-706.

28. Venkatesan C, Wainwright MS. Pediatric endocarditis and stroke: a single-center retrospective review of seven cases. Pediatr Neurol. 2008;38:243-7.

29. Earley C], Kittner SJ, Feeser BR, Gardner J, Epstein A, Wozniak MA et al. Stroke in children and sickle-cell disease: Baltimore-Washington Cooperative Young Stroke Study. Neurology. 1998;51:169-76.

30. Adams RJ. Stroke prevention and treatment in sickle cell disease. Arch Neurol. 2001;58:565-8.

31. Moser FG, Miller ST, Bello JA, Pegelow CH, Zimmerman RA, Wang WC et al. The spectrum of brain MR abnormalities in sickle-cell disease: a report from the Cooperative Study of Sickle-Cell Disease. AJNR Am J Neuroradiol. 1996;17:965-72.

32. Gerald B, Sebes JI, Langston JW. Cerebral infarction secondary to sickle cell disease: arteriographic findings. AJR Am J Roentgenol. 1980;134:1209-12.

33. Suzuki J, Takaku A. Cerebrovascular "moyamoya" disease. Disease showing abnormal net-like vessels in the base of the brain. Arch Neurol. 1969;20:288-99.

34. Angelo IL. Acidente vascular cerebral e outras complicações do Sistema Nervoso Central nas doenças falciformes. Rev Bras Hematol Hemoter. 2007;29:262-7.

35. Pegelow CH, Adams RJ, McKie V, Abboud M, Berman B, Miller ST et al. Risk of recurrent stroke in patients with sickle-cell disease treated with erythrocyte transfusions. J Pediatr. 1995;126:896-9.

36. Scothorn DJ, Price C, Schwartz D, Terrill C, Buchanan GR, Shurney W et al. Risk of recurrent stroke in children with sickle-cell disease receiving blood transfusion therapy for at least five years after initial stroke. J Pediatr. 2002;140:348-54.

37. Platt OS. Prevention and management of stroke in sickle cell anemia. Hematology Am Soc Hematol Educ Program. 2006:54-7.

38. Adams RJ, McKie VC, Hsu L, Files B, Vichinsky E, Pegelow C, et al. Prevention of a first stroke by transfusions in children with sickle cell anemia and abnormal results on transcranial Doppler ultrasonography. N Eng J Med. 1988;239:5-11.

39. Kuroda S, Houkin K. Moyamoya disease: current concepts and future perspectives. Lancet Neurol. 2008;7:1056-66.

40. Sebire G, Fullerton H, Riou E, deVeber G. Toward the definition of cerebral arteriopathies of childhood. Curr Opin Pediatr. 2004;16:617-22.

41. Dobson SR, Holden KR, Nietert PJ, Cure JK, Laver JH, Disco D, et al. Moyamoya syndrome in childhood sickle cell disease: a predictive factor for recurrent cerebrovascular events. Blood. 2002;99:3144-50.

42. Carlin TM, Chanmugam A. Stroke in children. Emerg Med Clin North Am. 2002;20:671-85.
43. Junqueira PA, Moura-Ribeiro MV. Moyamoya and Down syndrome: study conducted by meta-analysis. Arq Neuropsiquatr. 2002;60:274-80.

44. Amlie-Lefond C, Bernard TJ, Sébire G, Friedman NR, Heyer GL, Lerner NB, et al. Predictors of cerebral arteriopathy in children with arterial ischemic stroke: results of the International Pediatric Stroke Study. Circulation. 2009;119:1417-23.

45. Grabowski EF, Buonanno FS, Krishnamoorthy K. Prothrombotic risk factors in the evaluation and management of perinatal stroke. Semin Perinatol. 2007;31:243-9.

46. Carvalho KS, Garg BP. Arterial strokes in children. Neurol Clin. 2002;20:1079-100.

47. Haywood S, Liesner R, Pindora S, Ganesan V. Thrombophilia and first arterial ischaemic stroke: a systematic review. Arch Dis Child. 2005;90:402-5.

48. Jordan LC, Hillis AE. Hemorrhagic stroke in children. Pediatr Neurol. 2007;36:73-80.

49. Jordan LC, Johnston SC, Wu YW, Sidney S, Fullerton HJ. The importance of cerebral aneurysms in childhood hemorrhagic stroke: a population based study. Stroke. 2009;40:400-5.

50. Butros LJ, Bussel JB. Intracranial hemorrhage in immune thrombocytopenic purpura: a retrospective analysis. J Pediatr Hematol Oncol. 2003;25:660-4

51. Meyer-Heim AD, Boltshauser E. Spontaneous intracranial haemorrhage in children: aetiology, presentation and outcome. Brain Dev. 2003;25:416-21.

52. Jordan LC. Stroke in Childhood. Neurologist. 2006;12:94-102.

53. Donahue JG, Kieke BA, Yih WK, Berger NR, McCauley JS, Baggs $\mathrm{J}$, et al. Varicella vaccination and ischemic stroke in children: is there an association? Pediatrics. 2009;123:e228-34.

54. Jordan LC, van Beek JG, Gottesman RF, Kossoff EH, Johnston MV. Ischemic stroke in children with critical illness: a poor prognostic sign. Pediatr Neurol. 2007;36:244-6.

55. Lynch JK, Hirtz DG, DeVeber G, Nelson KB. Report of the National Institute of Neurological Disorders and Stroke workshop on perinatal and childhood stroke. Pediatrics. 2002;109:116-23.

56. deVeber G. Stroke and the child's brain: an overview of epidemiology, syndromes and risk factors. Curr Opin Neurol. 2002;15:133-8

57. deVeber G, Andrew M, Adams C, Bjornson B, Booth F, Buckley DJ, et al. Cerebral sinovenous thrombosis in children. $\mathrm{N}$ Engl J Med. 2001;345:417-23.

58. Kirkham FJ, Prengler M, Hewes DK, Ganesan V. Risk factors for arterial ischemic stroke in children. J Child Neurol. 2000;15:299-307.

59. Mergenthaler P, Dirnagl U, Meisel A. Pathophysiology of stroke: lessons from animal models. Metab Brain Dis. 2004;19:151-67.

60. Härtel C, Schilling S, Sperner J, Thyen U. The clinical outcomes of neonatal and childhood stroke: review of the literature and implications for future research. Eur J Neurol. 2004;11:431-8.

61. Kirton A, deVeber G. Cerebral palsy secondary to perinatal ischemic stroke. Clin Perinatol. 2006;33:367-86.

62. Golomb MR, MacGregor DL, Domi T, Armstrong DC, McCrindle BW, Mayank S, et al. Presumed pre- or perinatal arterial ischemic stroke: risk factors and outcomes. Ann Neurol. 2001;50:163-8.

63. Shi KL, Wang JJ, Li JW, Jiang LQ, Mix E, Fang F, et al. Arterial ischemic stroke: experience in Chinese children. Pediatr Neurol. 2008;38:186-90.

64. Rotta NT, da Silva AR, da Silva FL, Ohlweiler L, Belarmino E Jr, Fonteles VR, et al. Cerebrovascular disease in pediatric patients. Arq Neuropsiquiatr. 2002;60:959-63.

65. Ranzan J, Rotta NT. Ischemic stroke in children: a study of associated alterations. Arq Neuropsiquiatr. 2004;62:618-25.

66. Zimmer JA, Garg BP, Williams LS, Golomb MR. Age-related variation in presenting signs of childhood arterial ischemic stroke. Pediatr Neurol. 2007;37:171-5. 
67. Chadehumbe MA, Khatri O, Khoury JC, Alwell K, Szaflarski JP, Broderick JP et al. Seizures are common in the acute setting of childhood stroke: a population-based study. J Child Neurol. 2009;24:9-12.

68. Hirano M, Pavlakis SG. Mitochondrial myopathy, encephalopathy, lactic acidosis, and strokelike episodes (MELAS): current concepts. J Child Neurol. 1994;9:4-13.

69. Gauzzi LD, Tavares EC, Xavier CC, Corrêa FF. Use of posterior fontanelle in the ultrasound diagnosis of intraventricular/ periventricular hemorrhage. J Pediatr (Rio J). 2008;84:503-8.

70. Adams RJ, McKie VC, Carl EM, Nichols FT, Perry R, Brock K, et al. Long-term stroke risk in children with sickle cell disease screened with transcranial Doppler. Ann Neurol. 1997;42:699-704.

71. Deane CR, Goss D, O'Driscoll S, Mellor S, Pohl KR, Dick MC, et al. Transcranial Doppler scanning and the assessment of stroke risk in children with HbSC [corrected] disease. Arch Dis Child. 2008;93:138-41.

72. Steen RG, Emudianughe T, Hankins GM, Wynn LW, Wang WC, Xiong $X$, et al. Brain imaging findings in pediatric patients with sickle cell disease. Radiology. 2003;228:216-25.

73. Hutchison JS, Ichord R, Guerguerian AM, Deveber G. Cerebrovascular disorders. Semin Pediatr Neurol. 2004;11:139-46.

74. Kirkham FJ. Stroke in childhood. Arch Dis Child. 1999;81:85-9.

75. Matta AP, Galvão KR, Oliveira BS. Cerebrovascular disorders in childhood: etiology, clinical presentation, and neuroimaging findings in a case series study. Arq Neuropsiquiatr. 2006;64:181-5.

76. Gadian DG, Calamante F, Kirkham FJ, Bynevelt M, Johnson CL, Porter DA, et al. Diffusion and perfusion magnetic resonance imaging in childhood stroke. J Child Neurol. 2000;15:279-83.

77. Lechat P, Mas JL, Lascault G, Loron P, Theard M, Klimczac M, et al. Prevalence of patent foramen ovale in patients with stroke. $\mathrm{N}$ Engl J Med. 1988;318:1148-52.

78. DeVeber G. In pursuit of evidence-based treatments for paediatric stroke: the UK and Chest guidelines. Lancet Neurol. 2005;4:432-6.

79. Mekitarian Filho E, Carvalho WB, Troster EJ. Hyperglycemia and morbimortality in critically ill children: critical analysis based on systematic review. Rev Assoc Med Bras. 2009 (in press).

80. Greer DM, Funk SE, Reaven NL, Ouzounelli M, Uman GC. Impact of fever on outcome in patients with stroke and neurologic injury: a comprehensive meta-analysis. Stroke. 2008;39:3029-35.

81. Burak CR, Bowen MD, Barron TF. The use of enoxaparin in children with acute, nonhemorrhagic ischemic stroke. Pediatr Neurol. $2003 ; 29: 295-8$.
82. Monagle P, Chalmers E, Chan A, DeVeber G, Kirkham F, Massicotte $P$, et al. Antithrombotic therapy in neonates and children: American College of Chest Physicians Evidence-Based Clinical Practice Guidelines (8th Edition). Chest. 2008;133:887S-968S.

83. DeVeber G, Kirkham F. Guidelines for the treatment and prevention of stroke in children. Lancet Neurol. 2008;7:983-5.

84. Sträter R, Kurnik K, Heller C, Schobess R, Luigs P, Nowak-Göttl $U$. Aspirin versus low-dose low-molecular-weight heparin: antithrombotic therapy in pediatric ischemic stroke patients: a prospective follow-up study. Stroke. 2001;32:2554-8.

85. Ganesan V. Thrombolysis in paediatric arterial ischaemic stroke. Dev Med Child Neurol. 2009;51:90-1.

86. Amlie-Lefond C, Chan AK, Kirton A, deVeber G, Hovinga CA, Ichord $\mathrm{R}$, et al. Thrombolysis in acute childhood stroke: design and challenges of the thrombolysis in pediatric stroke clinical trial. Neuroepidemiology. 2009;32:279-86.

87. Arnold M, Steinlin M, Baumann A, Nedeltchev K, Remonda L, Moser SJ, et al. Thrombolysis in childhood stroke: report of 2 cases and review of the literature. Stroke. 2009;40:801-7.

88. Carlson MD, Leber S, Deveikis J, Silverstein FS. Successful use of rt-PA in pediatric stroke. Neurology. 2001;57:157-8.

89. Cannon BC, Kertesz NJ, Friedman RA, Fenrich AL. Use of tissue plasminogen activator in a stroke after radiofrequency ablation of a left-sized accessory pathway. J Cardiovasc Eletrophysiol. 2001; $12: 723-5$.

90. Guimarães IE, Ciasca SM, Moura-Ribeiro MV. Cerebrovascular disease in childhood: neuropsychological investigation of 14 cases. Arq Neuropsiquiatr. 2007;65:41-7.

91. Rodrigues SD, Cíasca SM, Moura-Ribeiro MV. Ischemic cerebrovascular disease in childhood: cognitive assessment of 15 patients. Arq Neuropsiquiatr. 2004;62:802-7.

\section{Correspondence:}

Eduardo Mekitarian Filho

Avenida Paulista, 200 - 70 andar - UTI Pediátrica

CEP 01310-000 - São Paulo, SP - Brazil

Tel.: +55 (11) 3016.4317

E-mail: emf2002@uol.com.br 